\title{
Associated Persons Substance Use Domain
}

National Cancer Institute

\section{Source}

National Cancer Institute. Associated Persons Substance Use Domain. NCI Thesaurus.

Code C147179.

A domain utilized for the submission of substance use records related to persons associated with the study subject. 